\title{
SOBRE AS NOÇÕES DE LÍNGUA E DISCURSO
}

\section{Ingo Voese ${ }^{(*)}$}

Resumo: Estudo das noções de língua e discurso a partir da Análise do Discurso tendo em vista as contribuições teóricas de Ducrot, Bakhtin, da teoria dos atos de fala e das próprias noções de evento e polissemia da linguagem.

Palavras-chave: Discurso, discursividade, evento

\section{Introdução}

Definir com precisão seu objeto e a maneira de abordá-lo sempre foi motivo de polêmicas e desafia, ainda hoje, a Análise do Discurso. O que, na verdade, está em discussão são opções teóricas que se referem à concepção da linguagem humana e, por isso, também da lingua e do discurso.

Nas diferentes formas de abordar a questão, porém, apesar das diferenças, há um acordo sobre a linguagem ser um produto da atividade histórica dos homens, cuja função seria a de preencher uma das condições que a sobrevivência e a organização dos indivíduos em grupo impõe: a comunicação.

Desse modo, é possível encontrar lingüistas que estudam a língua enquanto possibilidade de representação de uma realidade, ou os que a entendem como geradora de ações significadoras dos indivíduos. Há, ainda, os que se ocupam em estudar o significado, descrevendo as regras do uso da língua - que tanto podem ser de ordem interativa como cultural; e, finalmente, há aqueles que se propõem a analisar a produção de sentidos, incluindo dimensões mais amplas, como a da historicidade da linguagem.

Todas essas abordagens, porém, quase invariavelmente, focam a questão da produção de seníidos como se ela pudesse ser isolada de uma visão de totalidade do gênero humano, esquecendo-se de perguntar, por exemplo, 'por que produzir sentidos?', 'por que

(“) Docente do Mestrado em Ciências da Linguagem da Unisul. 
comunicar?', 'por que respeitar ou submeter-se a determinações culturais e históricas?', 'por que qualquer enunciado é ideologicamente marcado?', ou seja, se a linguagem é fundamental para a continuidade do gênero humano, as funções dela deveriam ser explicitadas tomando a generidade como referência. Ou melhor: o estudo da linguagem humana deveria poder explicar a produção de sentidos de um ângulo maior e que contemplasse questões que não se extinguem com uma imediaticidade da relação entre interlocutores, mas que, com a inclusão das noções de história e de ideologia, se situa nos limites do que ocorre em termos de sobrevivência e desenvolvimento do gênero humano.

Em outras palavras, se originalmente, a função da linguagem era apenas dar nomes às coisas do universo dos homens para, assim, garantir condições melhores de sobrevivência, quando as relações sociais se estruturaram de uma forma para além dos agrupamentos primitivos, outros objetivos, cada vez mais complexos, se constituíram e ultrapassaram a nomeação e a informação pura e simples, concepção que não raras vezes ainda nos dias atuais é desconsiderada no estudo do discurso.

Por isso, meu propósito neste texto, é retomar a reflexão sobre o discurso, problematizando, em primeiro lugar, as concepções de língua, ato de fala, evento cultural e acontecimento, para, depois, deter-me na de mediação, enquanto refração do reflexo.

\section{A Língua}

É até com uma certa tranqüilidade e freqüência que se afirma e ainda se aceita, em especial na escola, que a língua é um instrumento de comunicação, no sentido de que sla serve para transmitir informações, ou seja, entende-se que seja função predominante da língua a de representar algo.

É conveniente, contudo, considerar que quando uma explicação como essa - precisamente por seu caráter redutor e simplificador - ainda circula com certa freqüência nas esferas escolares e até acadêmicas, é que se deveria perguntar pelos motivos por que se insiste em considerar como função "total" o que é apenas parcial. E, por se tratar de algo tão importante na vida das pessoas, a ponto de ser impossível pensar não só a complexidade das sociedades 
humanas, como a própria sobrevivência delas sem a língua, torna-se imperioso problematizar sempre o que se diz de suas funções. E, por isso, da comunicação. Não que ela não seja um instrumento de comunicação, mas apenas isso? Não se estaria, talvez, minimizando ou apagando - e com que tipo de interesse - outras funções quando com tanta insistência se fala em instrumento de comunicação? Ou uma visão reducionista da linguagem teria algo a ver com uma concepção também constritora do homem?

Ora, quando se defende a concepção de que a função da língua é exclusivamente representativa, adota-se a noção de código. Se a língua, porém, fosse algo como um código, os enunciados deveriam remeter sempre a um mesmo significado, mesmo alterando-se, por exemplo, os contextos em que fossem produzidos.

Ducrot, já na década de 70 , abordava com muita propriedade esta questão, quando afirmava que:

Dizer que as línguas naturais são códigos destinados à transmissão da informação de um indivíduo a outro, é ao mesmo tempo, admitir que todos os conteúdos expressos graças a elas são exprimidos de maneira explícita.

Com efeito, por definição, uma informação codificada é, para aquele que sabe decifrar o código, uma informação que se dá como tal, que se confessa, que se expõe. O que é dito no código é totalmente dito, ou não de forma alguma (1977, p.13).

O que Ducrot quis dizer é que, se a língua fosse código, um enunciado como 'Está entrando frio pela janela' deveria ser apenas descritivo ou informativo e não deveria poder admitir o sentido, por exemplo, de 'Feche a janela'. Ou, então, 'Como você é inteligente' não significaria, nunca - como na ironia - 'Como você é burro'.

A expectativa de que a organização de vários enunciados em forma de texto, resolva o problema de estabelecer uma transparência de sentido também não se realiza. Observe-se a seguinte conversação:

'A' pergunta a ' $B$ ':

- Como vai o trabalho?

' $\mathrm{B}$ ' responde:

- A bomba não está funcionando. 
Fica evidente que a compreensão do diálogo exige, além da inferenciação de um 'vai mal' na resposta, ou a definição da profissão de B, ou a explicitação do sentido da palavra "bomba". E a língua parece implicar que a comunicação requer, para ser mais precisa, a cada palavra novas palavras explicativas, o que pode, talvez, ser entendido pelo fato de "que a tentativa de representar e fixar infinitas situações e realidades interiores em termos de formas concretas, leva a que surja a necessária polissemia das palavras" (LUKÁCS, 1986, v.II, p. 174) .

Por "necessária polissemia" talvez deva ser compreendida a concepção de que os recursos lingüísticos podem, por razões de economia, estar se referindo (como é o caso da palavra "bomba") a diferentes coisas, ou que a nomeação de coisas é sempre arbitrária e o sentido depende, em parte, de como os grupos sociais pensam e agem.

Mas não é só: uma mesma coisa pode ser nomeada por diferentes expressões, como é o caso de 'presidente da República', 'chefe do executivo', 'chefe da nação', 'Lula', etc.

$O$ fato, pois, de uma mesma palavra poder nomear diferentes coisas, e de uma mesma coisa poder ser nomeada por diferentes expressões, dá a primeira noção das dificuldades para se manter a noção de código, além de apontar para a complexidade da linguagem humana.

Outrossim, uma palavra como 'justiça' pode ser entendida como tendo um sentido que é comum ou genérico e um outro que difere de grupo para grupo social, de modo que 'fazer justiça' poderia significar, por exemplo, 'dar a todos a mesma coisa' ou, ao contrário, 'dar a cada um conforme suas necessidades'.

Essas questões que poderiam ser, dependendo das motivações do estudioso, problemas, ocuparam, em dada passagem da história do pensamento, os lógicos que sonhavam com uma linguagem que pudesse ser confiavelmente exata e precisa.

Frege (1978), por exemplo, um matemático, chegou provavelmente decepcionado - à conclusão de que uma palavra tem, sempre, um sentido que é social e de domínio de toda a comunidade e uma representação que é individual e não pode ser verbalizada: 
Enfim, espero ter conseguido problematizar, pelos exemplos que alistei, a noção de código utilizada para definir a língua e, sobremodo, fragilizar a idéia de que o processo de comunicação é algo simples e que não há dificuldades, em especial, para comunicar o que Frege chamou de representação.

\section{$\mathrm{O}$ ato de fala}

Ao que se disse acima - que já intranqüiliza a concepção de língua como código - se acrescentam novas dimensões quando se observar, por exemplo, que certos verbos (os chamados performativos) como 'prometer', 'absolver', 'jurar', 'excomungar', etc. têm um significado que se realiza como ação no ato de enunciação. $\mathrm{E}$ as ações dos homens - como se sabe - são regidas por acordos sociais. O uso de tais verbos, portanto, submete-se a regras da língua e da interação social.

À constatação de que os verbos performativos se referem a uma ação que se concretiza quando são enunciados, e de que falar também requer sejam cumpridos requisitos e regras que não são apenas lingüísticas e com o que o enunciante se compromete, é necessário incluir outros elementos, que não os lingüísticos, na descrição do processo de constituição dos sentidos. Por isso, Austin (1972) e Searle (1971) constituem, como seu objeto de estudo, os atos de fala.

O estudo dos atos de fala revela, desde logo, que utilizar a língua envolve mais do que apenas transmitir informações, especialmente quando se descobre que se pode, com ela, atuar. E o mal-entendido, o constrangimento, o mal-estar e o sofrimento que produzem certos enunciados não podem, pois, ser explicados, apenas, de um ponto de vista lingüístico ou comunicacional porque, em geral, eles são resultado da inobservância de regras sociais que orientam tanto as escolhas lingüísticas como o modo de usá-las.

No ato de fala, ou seja, no uso da língua na interação, o enunciante $f a z$ e age, em geral, motivado por intenções e interesses pessoais que nem sempre são explícitos, mas subentendidos, cuja compreensão, porém, depende não só do que diz o enunciante, mas também das regras que orientam os atos de fala. 
Em outros termos, o enunciante - como o entende a Teoria dos Atos de Fala - ao usar a língua, também se submete a determinadas regras sociais que, em primeiro lugar, dizem respeito à cooperação entre indivíduos. Ao falar, pois, deverá o indivíduo assumir, além do sentido instituído das palavras, determinados comprometimentos cooperativos como, por exemplo, o de ser sincero, quer seja em relação à informação, quer seja em relação aos propósitos.

Observando, entretanto, um enunciado como 'Lugar de homem não é na cozinha', algumas questões sérias em relação à concepção dos atos de fala tomam vulto porque nem sempre o enunciante terá a preocupação de ser explicita transparente, da relevância e da clareza, pois poderá querer implicitar, por exemplo, por diferentes razões, 'Saia da cozinha' ou 'Você está desrespeitando um costume nosso', 'A minha mulher não quer você na cozinha', etc.

Isso poderia estar indicando que nem sempre um enunciado tem apenas um caráter informativo ou revela as reais intenções do enunciante e com o que ele estaria disposto a se comprometer na interação, o que talvez explique, pelo menos parcialmente, por que se diz, correntemente, que, ao agir, não basta ter boas intenções...

Isto é: as relações sociais são bem mais complexas do que as que poderiam estimular sinceridades e de tal forma que nem sempre os indivíduos podem se comprometer com a cooperação: os homens, muitas vezes, também mentem, enganam, seduzem, coagem, ameaçam, etc., ou seja, se escondem e se protegem usando a língua e não se comunicam no sentido como acreditavam outrora (?) alguns lingüistas e os teóricos dos atos de fala: não que não haja informação, nem intenções, mas elas nem sempre se alinham com o princípio da cooperação, o que poderia estar a indicar que aos propósitos do enunciante se acrescentam dimensões de uma esfera mais ampla, a dos controles e dos rituais culturais.

\section{O evento cultural}

As pessoas, pois, valem-se, para interagir, não só da língua, mas também de regras de uso: ainda assim, respeitados os limites do jogo lingüístico e as regras conversacionais ou interativas, a comunicação parece fugir ao controle, motivo por que, na descrição 
do processo de produção de sentidos, será preciso incluir, ainda, outros elementos.

Observa-se, por exemplo, que o sentido 'Saia da cozinha' só se torna possível para 'Lugar de homem não é na cozinha' com auxílio do contexto, ou seja, o enunciado é informativo, sim, mas, considerando a situação imediata, ele pode também, entre outros sentidos possíveis, levar a entender que alguém ordena que um homem saia da cozinha. Pode-se concluir, pois, que a informação que pode ser retirada da leitura dos elementos lingüísticos não é tudo o que o enunciante poderia querer estar dizendo. Para produzir outros sentidos requer-se interpretar elementos que podem indicar, por exemplo, se o enunciante se responsabiliza pela veracidade da informação ou se está sugerindo, ordenando, ameaçando ou ironizando, etc.

$\mathrm{Na}$ verdade, quando os indivíduos interagem, também se submetem a regras que têm origem em esferas sociais mais distantes da situação imediata e, por isso, são diferentes das regras conversacionais: as ações interativas, apoiadas na linguagem, sempre recebem marcas que, inclusive, dizem respeito às atividades que desenvolvem os interlocutores.

Goffman (1985), por exemplo, desenvolve a idéia de que, na interação, os indivíduos se conduzem como atores numa cenografia em que determinados papéis orientam os atos, entendendo que, na sociedade, organizam-se, além de regras conversacionais, também regras que incluem e excluem determinadas condutas. E os indivíduos, ao interagirem, estariam representando também papéis sociais que nem sempre deveriam ser considerados inocentes, já que

$\mathrm{Na}$ maioria das sociedades parece haver um sistema principal ou geral de estratificação e em muitas sociedades estratificadas existe a idealização dos estratos superiores e uma certa aspiração, por parte dos que ocupam posições inferiores, de ascender às mais elevadas. (...) Verificamos habitualmente que a mobilidade ascendente implica na representação de desempenhos adequados e que os esforços para subir e para evitar descer exprimem-se em termos dos sacrifícios feitos para a manutenção da fachada (GOFFMAN, 1985, p. 41). 
A interação verbal, como se percebe, pode estar revelando que a informação que o enunciado contém e o ato que o enunciante realiza ao pronunciá-lo, também se referem a um determinado papel que se pode exercer em determinada cultura, isto é, uma outra comunicação estaria também se processando e o ato de fala deveria ser entendido também como um evento cultural.

Em outros termos, considerando que o enunciado 'Lugar de homem não é na cozinha' pode gerar também, ao invés de 'Saia da cozinha', uma explicação do tipo 'Em nosso meio não é costume o homem desenvolver atividades na cozinha', será necessário aceitar que o uso da língua, em determinado contexto, possibilita não apenas uma informação e um ato de fala, mas também a manifestação de um traço cultural da sociedade, i.é., uma valoração de condutas sociais. Desse modo - quando o ato de fala passa também a ser um evento cultural - ampliam-se os limites do contexto que precisa ser levado em conta na descrição do processo de constituição dos diversos sentidos que podem ocorrer: além da língua, dos atos de fala, é preciso incluir as inferenciações culturais, conforme se pode observar num diálogo como o seguinte:

— Você vai à solenidade?

- Não tenho roupa.

A inferência que o primeiro enunciante deve fazer diz respeito a que a solenidade, dentro do universo cultural do segundo enunciante, exige que as pessoas se apresentem com um determinado tipo de vestimenta que seu interlocutor diz não possuir em "não tenho COM A COOPERAÇÃO roupa".

O diálogo aciona uma inferenciação que se refere a uma esfera mais ampla do contexto que incide como determinação sobre o uso da língua e formulará novas questões, especialmente, quando se sabe que os interlocutores, ao representarem papéis sociais, fazem-no ocupando determinados lugares sociais. É por isso que dizer 'Lugar de homem não é na cozinha' reflete também valores ou valorações de papéis e, como desdobramento, dos lugares sociais que, historicamente, se constituíram como uma hierarquia de forças. 


\section{O acontecimento}

Ao incluir, na produção dos enunciados, a dimensão histórica, amplia-se ainda mais a questão da complexidade do uso da língua, de modo que um enunciado como 'Lugar de homem não é na cozinha', cujos sentidos poderiam, no plano imediato da enunciação, ser considerados um tanto "inocentes", já que ocorrem uma informação, um ato de fala e um evento cultural, assume também uma forma de valoração de um lugar social, ou seja, aquilo que o homem diz (ou não) e faz (ou não) em determinado lugar social vai ter mais ou menos prestígio e poder. Em outros termos, ao enunciar 'Lugar de homem não é na cozinha', o enunciante poderia estar manifestando um valor como, por exemplo, 'Ou quem é que manda nessa casa? O homem ou a mulher?', o que revelaria que só a mulher deveria ocupar o lugar onde se cozinha - e só ela deveria poder (?) falar sobre os assuntos ligados a esse lugar da casa cuja "força" de fala seria inferior ao de outros lugares por onde, por oposição, deveria transitar preferencialmente o homem.

A distribuição, pois, dos papéis de acordo com os lugares sociais que os indivíduos ocupam, corresponde a uma hierarquização que concretiza uma diferenciação quanto ao valor e à importância do que se diz em cada instância social, ou seja, há valores de papéis sociais que se agregam às falas, ungindo-as com maior ou menor força para produzir efeitos de poder. E se nos enunciados, então, transitam, também, valores sociais dessa ordem, pode-se argüir que, se muitas vezes o que se diz pode levar a julgamentos e punições, não é porque houve insucesso no processo de comunicação. Há outras dimensões das relações humanas com que a utilização da língua acha-se envolvida e isso, em geral, não é dito explicitamente. Pode-se, por exemplo, entender hoje que alguém alguma vez possa ter sido condenado à morte por ter dito que a Terra é redonda? E mais: é isso coisa só do passado? Não existem ainda hoje coisas ditas e não-ditas, especialmente, em jornais e revistas, às quais só poucos têm acesso?

Exemplifico melhor: mesmo que se aceite que os indivíduos se comunicam, valendo-se da língua e que a expressão 'comunicar-se' possa sugerir a interação cooperativa, ficaria um pouco difícil admitir a simetria entre os atos de fala dum dono de supermercado - que cobra preços exorbitantes, engana quanto à qualidade e ao peso, ou frauda conteúdos - e de seu empregado que leva, eventualmente, sem pagar, um produto qualquer de que necessita e que não pode comprar porque 
seu salário não o permite: a palavra 'roubar' caberia apenas para o ato de um dos interlocutores. A divergência de interpretações, na verdade, produz e revela o conflito social, e o estudo do uso da língua necessitará incluir também essa dimensão sócio-histórica.

Pode-se compreender, então, que um enunciado como 'Lugar de ladrão é na cadeia' não precisa estar se referindo necessariamente a todo e qualquer indivíduo que roube e que, em 'Todos os homens têm direito à vida', 'todos os homens' pode não só estar eliminando mulheres e crianças, mas também negros, pobres etc. e referir-se apenas a alguns privilegiados.

Uma outra questão que deve ser considerada importante na reflexão diz respeito ao uso da língua na mídia, também chamada de meio de comunicação social, precisamente porque, se são esses os instrumentos dos quais a sociedade depende em termos de circulação e transmissão de informações, seria de esperar que a primeira preocupação fosse, aí, com a precisão e a transparência possível, em termos de comunicar, o mais exata e imparcialmente, temas e fatos de que depende o desenvolvimento social. Sabe-se, porém, que, tanto a TV como o jornal e o rádio, dentro da nossa sociedade, devem a sua existência não ao comprometimento com o que importa ao gênero humano, mas com a priorização dos efeitos de manipulação que produzem certas notícias junto ao público. Ou seja, selecionam-se e verbalizam-se somente as informações que podem preencher as expectativas das empresas patrocinadoras dos programas onde seus produtos são divulgados e prestigiados. Nenhuma empresa, por exemplo, divulgará seus produtos em jornais que têm poucos leitores ou cujos leitores pertençam à camada social de pequeno poder aquisitivo, o que revela que se instala, em geral, nesse meio, um tipo de cumplicidade em que interesses particulares se sobrepõem aos coletivos.

Em outros termos, não estaria equivocado quem dissesse que, quase sempre, os meios de comunicação social desinformam, ou não comunicam tudo da forma mais imparcial porque assim atendem os interesses de determinados segmentos sociais: há informações a dar e há as que devem ser omitidas, há um modo de dizer e outros a desconsiderar. Embora se insista com a idéia da neutralidade da mídia, sabe-se que 
A linguagem pode ser usada para impedir a comunicação de informações para grandes setores da população. Todos nós sabemos quanto pode ser entendido das notícias políticas de um Jornal Nacional por indivíduos de baixo nível de educação. A linguagem usada e o quadro de referências dado como implícito constituem um verdadeiro filtro da comunicação de informações: estas podem ser entendidas somente pelos ouvintes já iniciados não só na linguagem padrão, mas também nos conteúdos a ela associados (GNERRE, 1985,p.15).

Lembrando, então, mais uma vez, que o uso da língua não se reduz a algo como (de)codificação de uma mensagem, nem a interações e eventos culturais, parece que a produção de sentidos não sugere uma transparência e uma inocência, antes, o contrário. Os malentendidos são mais freqüentes do que se espera ou pensa e as interpretações que interessam ao exercício do poder e geram conflitos representam problemas maiores do que o fato de fazer apenas uma leitura errada.

Ora, tal constatação implica dizer que a descrição da produção de sentidos precisa, também, responder a por que e como se dá o fato de uma dada informação, um determinado ato de fala ou evento cultural, e não outros, surgirem no tempo e no espaço circunstanciais, ou seja, interessa também saber por que, em dadas circunstâncias históricas e sociais, faz-se uma distinção quanto à presença de homem ou mulher, por exemplo, na cozinha e que efeitos de sentido, em termos de poder, isso provoca nas respectivas falas.

É exatamente por isso que também o poder do lugar social de atuação do enunciante - o grupo a que pertence - torna-se importante na produção do sentido. Se, por exemplo, alguém falar 'Lugar de homem não é na cozinha', torna-se crucial aceitar que assim também pensa o grupo social a que pertence o enunciante, e que uma instituição abriga seu enunciado para que ele possa contribuir para a consolidação ou transformação de determinados valores e hierarquizações de falas. E, por isso, o enunciado não representará mais apenas um ato ou um evento em uma dada situação, limitada e controlada pelas ações de interlocutores, mas também um produto que, na sua construção, se submete a determinações bem mais intrincadas e complexas de rituais de controles e de regras de produção. 
Torna-se obrigatório, pois, admitir a importância de um contexto bem amplo na descrição da produção de sentidos do enunciado, levando em conta que "A situação social mais mediata e o meio social mais amplo determinam completamente e, por assim dizer, a partir do seu próprio interior, a estrutura da enunciação" (Bakhtin, 1986, p. 113), o que quer dizer que "Na maior parte dos casos, é preciso supor, além disso, um certo horizonte social definido e estabelecido que determina a criação ideológica do grupo social e da época a que pertencemos" (p.112).

Esse "horizonte social definido" não pode, porém, ser entendido como uma realidade estática. Pelo contrário: Bakhtin referese à esfera da generidade como processo permanente que determina que todo e qualquer enunciado seja também uma ocorrência que obedece a regras e rituais culturais de um aparecer histórico.

Se, portanto, a enunciação não dispensa considerar a situação - não só imediata - mas também histórica, o enunciado, na verdade, assume estatuto de acontecimento. Essa concepção, por sua vez, terá, como efeito, entender o enunciado, desde o nível da sentença ao do texto, como um discurso. Em outros termos, qualquer enunciado deverá ser entendido não só quanto à estruturação interna, como também em relação às conexões que estabelece com diferentes esferas do gênero humano, o que corresponde à sua discursividade.

Isso quer dizer, outrossim, que o enunciado, enquanto texto, tem uma estrutura interna própria e uma discursividade, entendida como determinação exterior que fixa o horizonte de possibilidades do acontecimento.

E, por ser acontecimento - sempre irrepetível - o discurso também deve ser abordado do ponto de vista do que ele significa para a continuidade do gênero humano.

Ora, a compreensão do texto como discurso depende fundamentalmente de como se entende essa relação entre uma lógica do enunciado e a da determinação exterior, tanto da esfera imediata, como da mediata.

Por isso, uma primeira e importante concepção que pode se fazer útil é a de heterogeneidade social, nos termos, por exemplo, que Heller (1972) formaliza quando diz que 
[...] o indivíduo pode pertencer a numerosos grupos, na medida em que o fato de pertencer a grupos define-se através de uma certa analogia de interesses e objetivos, bem como finalidades, interesses e atividades importantes, ao lado de outros que não o são na mesma medida. Isso origina uma hierarquização de "nossos" grupos, distinguindo principalmente entre os grupos que representam nossos principais interesses, objetivos e atividades [...] e os grupos que se relacionam com nossos interesses, atividade e objetivos secundários, inessenciais (p.67).

Os interesses e os objetivos correspondem, pois, a formas de suprir necessidades que uma situação social cria, ou seja, eles resultam das incessantes atividades que se desenvolvem nos grupos, de modo que se pode dizer que o que resulta desse processo, o produto, entendido como cultura, sempre é um marco que precisa ser reproduzido para servir de orientação e de motivação para novas atividades dos indivíduos.

Em outras palavras, as singularizações do genérico humano, dum ponto de vista histórico, leva à constituição dos grupos que, por sua vez, (re)produzem a heterogeneidade social, ou seja:

1. Há necessidades e interesses que geram atividades de organização dos indivíduos: o agrupamento significa a possibilidade de melhores condições de resolução de problemas e de superação de dificuldades no contexto da heterogeneidade social. Os indivíduos, porém, para poderem organizar-se de modo produtivo, precisam apropriar-se não só do que os une, mas também do que gera a heterogeneidade: a amplitude das apropriações da realidade social vai determinar se aumentam ou não as condições de manutenção dos interesses e a consecução dos objetivos.

2. O fato de os indivíduos procurarem organizar-se em grupos e terem que atuar sobre o conflito que os diferentes interesses geram, faz com que o discurso seja, necessariamente, dialógico, porque

Nossa fala, isto é, nossos enunciados (...) estão repletos de palavras dos outros, caracterizadas, em graus variáveis, pela alteridade ou pela assimilação, 
caracterizadas, também em graus variáveis, por um emprego consciente e decalcado. As palavras dos outros introduzem sua própria expressividade, seu tom valorativo, que assimilamos, reestruturamos, modificamos (BAKHTIN, 1992, p. 314).

A dialogia, pois, é inerente a todo discurso e, na medida em que diz respeito a vozes que antecederam a do enunciante e às que poderão sucedê-la, explicita a dupla função da linguagem: não há enunciado que não exiba traços do produto histórico da atividade dos homens e que, objetivado, não possa servir de referência para que novos enunciados sejam construídos e nos quais se manifeste uma maior ou menor superação do que estava socialmente posto.

Ora, isso quer dizer que o discurso é, também, como a realidade social, heterogêneo, ou melhor, revela uma polifonia que pode:

1. ser resultado da alteridade que marca os atos de fala, quando a citação do enunciado de outrem se faz através das inúmeras formas de inserção que o discurso aceita;

2. ser também, nos limites da atividade coletiva, produto da pressão de interesses de um determinando grupo social, em termos de a repetição de vozes marcar uma identidade e uma valoração do modo de enunciação;

3. ser entendida, em casos bem específicos, como resultado das relações entre os diferentes grupos sociais, de modo que enunciados de um lugar social, eventualmente, passam a ser usados por enunciantes de outro.

Exemplificando: Uma forma de polifonia percebe-se em casos como no enunciado 'João disse que viria'. Há duas vozes presentes no enunciado, considerando-se João aquele que disse o que o enunciante diz: o ato fisiológico pertence em 'João disse que viria' de fato a um só enunciante, mas na constituição do sentido do enunciado, aparece, como que num plano secundário, o enunciante 'João' dizendo 'eu irei'. Assim, alguém disse o que João disse. O mesmo acontece também com o enunciado 'João virá' porque alguém (agora não necessariamente João) deve ter dito que João viria.

Por outro lado - tomando como exemplo a idéia de que a cozinha não é lugar de homem -, pode haver diferentes modos de enunciação para veicular as vozes que manifestam uma concordância, 
tais como 'João disse que lugar de homem não é na cozinha', 'Há pessoas que pensam que...', 'Uma minoria acha que...', 'Talvez alguém ainda pense que...', 'Infelizmente se diz que...', 'Lugar de homem não é na cozinha', etc.

Essa dimensão polifônica do discurso dá conta, pois, de que um enunciado como 'Lugar de homem não é na cozinha' pode revelar não só a voz de um indivíduo, mas também as de um grupo: há, evidentemente, a presença de quem enunciou, mas também a de indivíduos do grupo a que ele pertence e que avaliam e avalizam o sentido genérico do dito. Isto é: o enunciado representa também as vozes repetidas de muitos homens, as quais imbutem, no dito, um valor menor para o lugar social 'cozinha' e a diminuição de prestígio e poder do segmento masculino se eventualmente ocupasse esse espaço.

Pode ocorrer, ainda, que no enunciado se localizem vozes que não pertencem ao grupo do enunciante como, por exemplo, no caso de uma mulher, com um propósito irônico, dizer 'Lugar de homem não é na cozinha', o que estaria revelando que também o conflito e a disputa se refletem, como polifonia, no discurso, porque o enunciante, ao estabelecer relações entre seus interesses e os instituídos nos diferentes grupos, forçosamente incluirá, na sua voz, aquelas que têm as mesmas motivações e silenciará as que se opõem. Isto é: lembrando o que disse Heller sobre os interesses que dão origem aos grupos sociais, pode-se também entender a polifonia como o reflexo de uma das dimensões da estrutura social e que diz respeito ao conflito que tanto leva os indivíduos a manterem a integridade do grupo, zelando e reforçando as características de um modo de enunciar através não só da reprodução de um ethos, como também da incorporação estratégica de enunciados de segmentos sociais conflitantes, atividade em que a realidade social, de um certo modo, orientará as escolhas do indivíduo quanto aos itens lexicais, modalizações, operações argumentativas, gêneros, estilo, etc.

Não se deve, pois, quando se fala da generidade humana, esquecer que, com a divisão social do trabalho e com o conflito de classes, culturas, raças, gênero, etc., valorizaram-se diferenciadamente os lugares sociais que ocupam ou podem ocupar os indivíduos quando atuam. Do ponto de vista histórico, isso produz a necessidade de os indivíduos se apropriarem da heterogeneidade e do que ela gera, pois "[...] estão sempre inseridos em tradições históricas" o que envolve a 
reprodução de uma "gama complexa de significados e valores que são passados de geração a geração” (THOMPSON, 1990, p. 360).

Apropriar-se, enfim, das "tradições históricas" é compreender que a valorização diferenciada dos lugares sociais corresponde a uma hierarquização que pressiona as interações dos homens e, por isso, no discurso se marca, necessariamente, "a influência poderosa que exerce a organização hierarquizada das relações sociais sobre as formas de enunciação" (BAKHTIN, 1986, p. 43).

Os lugares sociais, do modo como estão organizados quanto a valores e prestígios, também hierarquizam as vozes, estabelecendo tensões, mais ou menos conflitivas, que geram concordâncias, contrapontos e contradições. Não se pode, por isso, abordar a polifonia como se ela fosse apenas a inclusão das vozes de indivíduos isolados, já que "[...] as relações de produção e a estrutura sóciopolítica que delas deriva determinam todos os contatos verbais possíveis [...] todas as formas e os meios de comunicação verbal" (BAKHTIN, 1986, p.42).

$\mathrm{O}$ apoio que busco em Bakhtin, permite entender que as determinações sociais, (a discursividade) que incidem sobre a produção do discurso podem ser distribuídas em três níveis:

1. Formas de comunicação verbal ou formas discursivas - que denominarei formas de discursividade - correspondem às condições que se originam da heterogeneidade social a partir de classe, raça, sexo, religião, cultura, nacionalidade, etc. $\mathrm{O}$ fato, pois, de pertencer a um determinado grupo, ao mesmo tempo que impõe modos de enunciação, também avaliza a atividade do enunciante, assim que o enunciado apresenta uma dimensão da discursividade que resulta de determinações que fogem do raio de intervenção do indivíduo: ninguém pode, por exemplo, alterar raça, sexo ou nacionalidade a que pertence, e terá dificuldade para fazê-lo quanto classe, religião, cultura, etc. porque os caminhos e os acessos às mudanças sofrem controles, em geral, bastante eficientes, dentro da hierarquização construída.

2. Modos de enunciação que se constituem ou como padrões e modelos mais ou menos estáveis de produção de enunciados, ou como possibilidades que abrangem campos distintos como 
o dos gêneros discursivos, o das variedades lingüísticas e o das operações lingüísticas.

São gêneros discursivos os que caracterizam os enunciados da Política, do Direito, da Poética, das reuniões sociais, da oralidade e da escrita, da família, etc., todos, porém, determinados pela hierarquização constituída no âmbito das formas de discursividade, de maneira que, conforme Bakhtin (1992), os gêneros podem ser primários (mais simples, como o da família) e secundários (mais complexos, como o científico), o que não impede de se encontrar', neles, a manifestação de uma intencionalidade do enunciante, ou seja, "a variedade dos gêneros do discurso pressupõe a variedade dos escopos intencionais daquele que fala ou escreve" (BAKHTIN, 1992, p. 291).

As variedades lingüísticas correspondem a modos de enunciação que poderiam também ser entendidos como dialetos sociais e regionais, ou seja, são usos diferenciados da língua no que se refere à pronúncia, às operações gramaticais, à nomeação, à significação, etc. Também aqui a hierarquização social se faz sentir porque há variedades com maior e menor prestígio.

As operações lingüísticas dizem respeito às escolhas no âmbito da língua: itens lexicais, modalizadores, operadores argumentativos e arranjos sintáticos.

Enfim, os modos de enunciação são a tal ponto importantes para a comunicação verbal que "se não existissem [...] e se não os dominássemos, se tivéssemos de criá-los pela primeira vez no processo da fala (...) a comunicação verbal seria quase impossível" (p.302).

3. Temas que se constituem enquanto produto e referência da atividade dos indivíduos e, por esta ser diferenciada nos inúmeros segmentos sociais, pode-se, obviamente, conceber uma heterogeneidade temática, igualmente hierarquizada quanto a um maior ou menor prestígio social. Isto é: há temas que são considerados mais ou menos relevantes, dependendo da força do lugar social onde são gerados. 
Se as formas de discursividade, os modos de enunciação e os temas compõem o que, para Bakhtin, são as condições de comunicação ou de interação social, é possível entendê-las como uma unidade orgânica que equivale a condições de produção da mediação discursiva.

A heterogeneidade social constrói, pois, historicamente, em diferentes planos, o horizonte e os limites das condições de produção do discurso, onde se observa uma hierarquização que perpassa as formas de discursividade, os modos de enunciação e os temas: um discurso masculino, em geral, se impõe ao feminino, assim como o do branco ao do negro, etc.; os gêneros jurídico, científico, filosófico, religioso são mais valorizados do que o familiar, e a variedade linguística considerada culta marca as outras variedades como incultas.

Isso posto, pode-se entender que, pelo fato de a sociedade ser uma estrutura em que não só os indivíduos interagem, mas também os diferentes grupos estabelecem relações mais ou menos complexas, mais ou menos tensas, que se modificam historicamente, as formas de discursividade determinam, em parte, as interações verbais quanto ao que pode ser reproduzido e transformado.

E se, quanto às formas de discursividade, o espaço para fazer escolhas é mais reduzido, quanto ao modo de enunciação, ao contrário, descortina-se a possibilidade para uma atividade intensa e participativa do enunciante, já que "o querer-dizer do locutor se realiza acima de tudo na escolha de um gênero do discurso. Essa escolha é determinada em função da especificidade de uma dada esfera da comunicação verbal, das necessidades de uma temática (do objeto do sentido), do conjunto constituído dos parceiros, etc." (BAKHTIN, 1992, p.301).

Ora, a escolha é uma atividade que resulta de outra, anterior e avaliativa, processo que, por representar um querer do enunciante, pode promover alterações quanto à hierarquização que perpassa as condições de produção do discurso de modo que se observa uma constante reconfiguração histórica delas. Isto é: não há um engessamento dos condicionamentos que resultam de se saber quem pode enunciar, em que situação histórica, como, o quê, porque, se a hierarquização da discursividade se impõe aos modos de enunciação e aos temas, estes, por se constituírem como espaços de 
constrangimentos sociais mais diluídos e de maior liberdade do enunciante, no movimento de refração da atividade dos indivíduos, podem propiciar a transformação daquilo que os determina.

A superação do posto pode, portanto, ocorrer mesmo sob as mais fortes pressões sociais, do que a prática pedagógica, por seus objetivos específicos e pelos efeitos que pode produzir, é um excelente exemplo, já que a escola pode ser considerada um lugar muito especial para atuar sobre o conflito de interesses, motivo por que o segmento social hegemônico, compreensivelmente, instala, aí, procedimentos de vigília e de controle.

Para exemplificar essa correlação entre formas de discursividade, modos de enunciação e temas, observo três recortes de textos que pertencem à prática pedagógica: o lugar social dos enunciantes é a academia - que, porém, não pode, por conta da heterogeneidade social, ser definida como um lugar homogêneo de enunciação -, o tema é o ensino e os modos de enunciação se diferenciam entre um gênero técnico-científico, um quase literário e um filosófico.

Pelo caráter conservador da escola, seria de esperar, pois, que dificilmente houvesse uma "rebeldia" discursiva na prática pedagógica. Observe-se, porém, a distância do ethos de propostas educacionais entre as que selecionei de tantas que circulam na academia. Nos textos, é possível verificar não apenas diferentes orientações para uma prática pedagógica, mas também, como isso se reflete na modelagem e organização do discurso: o primeiro é mais formal, disciplinado e disciplinador, enquanto os outros apresentam, diferenciadamente, marcas de rebeldia, provocação e desafio. (Os grifos são meus e pretendem apontar algumas diferenças que considero significativas.) :

I - Entre os mais sérios problemas enfrentados pelo professor está a decisão sobre o que deverá fazer a fim de ajudar seus alunos a alcançarem os objetivos que deseja. Certamente a formulação de metas específicas é uma pré-condição necessária ao planejamento de um ensino efetivo. [...] O professor ainda precisa possuir algumas maneiras de identificar e ordenar as atividades que irão favorecer suas chances de sucesso (POPHAM e BAKER, 1978, p.7). 
II - 0 professor sedutor incita à construção de um imaginário que procure sua autonomia, quebrando o útero e deslocando o afeto protetor para o prazer sem culpa. $\mathrm{Na}$ didática da sedução, busca-se a realização coletiva de um imaginário carnavalizado, onde todos possam despertar para o saber do acasalamento da política com o prazer, da subversão com a alegria, das verdades com a poesia e, finalmente da democracia com a polifonia das significações. Um professor sedutor deseja conviver com alunautas indiferentes às boas utilizações do saber.

Para quem gosta de bordoadas, a aula de sedução as distribui com fartura, mas calmamente. Aí está um dos segredos de Barthes: a cortesia impecável como insuspeita arma de subversão. Ele entendia que a força subversiva das palavras estava mais no desvio inesperado do seu sentido que na fetichização de alguns estereótipos neurotizados. A palavra calma, serena, é uma palavra democrática, que acolhe e estimula as diferenças sem pô-las em conflito, e que convida a vivê-las em pluralidade. Um convívio que, evidentemente, não exclui os desenvolvimentos dos antagonismos (WARAT, 1985, p. 84).

III - A educação é um ato de amor, por isso, um ato de coragem. Não pode temer o debate. A análise da realidade. Não pode fugir à discussão criadora, sob pena de ser uma farsa. Como aprender a discutir e a debater com uma educação que impede? (FREIRE, 1991, p. 69).

O discurso professoral, pois, como qualquer outro, apresenta, ora mais, ora menos nítidas as marcas da maneira como os diferentes grupos sociais concebem a função de professor: se o grupo social hegemônico entender que a educação deve ser fundamentalmente um processo de domesticação e de reprodução cultural, a forma de discursividade exercerá pressão sobre o modo de enunciação no sentido de que o enunciado se apresente dogmático e autoritário.Toda essa pressão, porém, ainda é insuficiente para anular a possibilidade de a orientação dogmatizadora - que é feita via discurso - gerar, como nos exemplos que apresentei, um discurso rebelde, precisamente porque o texto construído pelo enunciante, uma vez socializado, foge 
dos controles do autor e torna-se mais ou menos imprevisível quanto aos efeitos que produzirá nas relações dialógicas com outros discursos.

Por isso, os inúmeros controles sobre a produção e o acesso ao discurso lembram que a heterogeneidade social significa um certo risco, porque, se a cada indivíduo e a cada segmento social correspondem diferentes interesses e objetivos que podem ser acionados sob orientação de diferentes sistemas de referência, não é difícil de prever um conflito entre o que vai ser considerado como essencial reproduzir e o que necessita de transformações.

Ora, os interesses e os objetivos dos grupos protagonizam, por efeito da atividade dos indivíduos, o estabelecimento, nem sempre explícito e preciso, de linhas demarcatórias de um projeto de socialidade. Isto é: o grupo passa a centrar suas atividades na consecução de um ideal de sociedade que, certamente, contemplará seus interesses e objetivos:

Nos referimos ao fato de algumas idéias jogarem um papel chave na escolha das alternativas a serem objetivadas em cada momento histórico. Tais idéias compõem, sempre, uma visão de mundo, e auxiliam os homens na tomada de posição frente aos grandes problemas de cada época, bem como frente aos pequenos e passageiros dilemas da vida cotidiana. [...] esse conjunto de idéias é denominado ideologia (LESSA, s.d., p. 24).

Percebe-se, nessa concepção de ideologia (que difere da de falsa consciência) que as idéias-chave, entendidas como referências, têm uma função positiva porque, sem elas, o grupo ficaria sem rumo e se esfacelaria rapidamente, o que, de outra maneira, explica que o discurso, como mediação da atividade vital dos homens, se constitui na observância desse projeto de socialidade, de modo que, conforme Bakhtin (1986), toda palavra carrega um índice de valor, produto das atividades avaliativas que os indivíduos dos grupos realizam, apoiados nas referências-chave, ou seja, na ideologia.

Outrossim, considerando a ideologia uma mediação valorativa, as hierarquizações das formas de discursividade, dos modos de enunciação e dos temas dos enunciados devem ser entendidas como efeitos ideológicos. Ou melhor: o discurso sempre é 
ideológico, o que diz que ele traduz, na sua materialidade, como marcas, o conflito de diferentes projetos de socialidade.

É evidente, pois, que, pelos efeitos que podem produzir os sentidos do discurso sejam objeto de disputas e, por isso, de tentativas de controle. Isto é: o controle de sentidos parte do pressuposto de que ele poderia representar igualmente o controle do conflito. E esse procedimento - que prescinde tanto da negociação de acordos como do uso coercitivo da força - se concretiza através da ação ideológica que, como estratégia, busca homogeneizar, hierarquizando, o que é heterogêneo para, desse modo, preservar interesses específicos de um determinado grupo. Os objetivos da ação ideológica perpassam, pois, todo o tecido social, ou seja, o processo envolve avaliações que hierarquizam os sistemas de referência o que, por sua vez, conduz à hierarquização de formas de discursividade, modos de enunciação, funções e atividades, costumes, produtos, etc., mas - e isso é uma especificidade da ação ideológica - cuidando para que não sejam revelados os reais objetivos da interferência na heterogeneidade, assim como leio em Goldmann (1979, p.20):

A situação modifica-se outra vez quando nos encontramos diante de vários grupos de indivíduos cujos objetivos são diferentes ou mesmo antagônicos. Suponhamos que um dentre esses grupos tenda a realizar na vida social uma transformação que outro grupo tem interesses de impedir a qualquer preço. Do ponto de vista desse último, qualquer que seja a verdade ela não deve ser sabida e, sobretudo, não deve ser divulgada, pois ela pode favorecer a ação do grupo contrário.

Desse modo, sem um olhar atento dirigido ao que é estratégia ideológica, pode parecer que a sociedade - e o discurso também - se apresentem como realidades relativamente constantes e, de certa forma, tranqüilas, onde eventuais rupturas e rebeldias poderiam ser consideradas apenas como desvios de ordem individual, como se as apropriações e as objetivações que ocorrem nos diferentes grupos pudessem ser orientadas por um único sistema de referências. Cria-se, desse modo, a falsa impressão de que as dimensões do conflito são bem menos complexas, porque apenas haveria que impedir rebeldias e inconformidades "injustificadas" contra as hierarquizações "naturais". É essa impressão simplificadora que a ação ideológica procura (1) "struir para poder "resolver" o risco do conflito. 
Entendo, portanto, que a ação ideológica, no conflito social, constrói, sem expor a lógica do processo, uma hierarquização de sistemas de referência, para o que são alocados recursos tais como estratégias discursivas, rituais institucionais, regras conversacionais e expressões lingüísticas. $\mathrm{O}$ discurso pode, pois, ser um recurso que um grupo utiliza para tentar instalar um controle mais ou menos eficiente sobre quais sentidos são ou não convenientes à manutenção de uma hierarquização que privilegia seus interesses e produz efeitos de poder. A eficiência, enfim, da ação ideológica não pode ser subestimada, pois

Deve-se enfatizar que o poder da ideologia dominante é indubitavelmente enorme, não só pelo esmagador poder material e por um equivalente arsenal político-cultural à disposição das classes dominantes, mas sim, porque esse poder ideológico só pode prevalecer graças à posição de supremacia da mistificação, através da qual os receptores potenciais podem ser induzidos a endossar, "consensualmente", valores e diretrizes práticas que são, na realidade, totalmente adversos a seus interesses vitais (MÉSZÁROS, 1993, p. 10).

Conceber todo e qualquer discurso como ideologicamente marcado significa que é incontornável a pressão do conflito sobre as interações sociais, pois os interlocutores, quando visam a convencer os de outro grupo para que aceitem a disposição hierarquizada do que compõe a heterogeneidade social, valem-se de diferentes recursos discursivos que podem efetivar a ação ideológica de tal maneira que, sem revelar os interesses, possam produzir os efeitos de convencimento e de poder desejados. do grupo,

E, por isso, além de considerá-la fundamental à sobrevivência

[...] estudar a ideologia é estudar as maneiras como o sentido serve para estabelecer e sustentar relações de dominação. [...] Não é essencial que as formas simbólicas sejam errôneas e ilusórias para que elas sejam ideológicas. Elas podem ser errôneas e ilusórias. De fato, em alguns casos, a ideologia pode operar através do ocultamento e do mascaramento das relações sociais, através do obscurecimento ou da falsa interpretação das situações (THOMPSON, 1995, p. 76). 
Interessa-me, aqui, evidentemente, manter a concepção de que a ideologia não tem como função original a dominação, mas diante do conflito e da luta pelo poder de intervir nos rumos do desenvolvimento do gênero humano, com ela os indivíduos organizam estratégias para defender seus interesses, o que justifica que "estudar a ideologia é estudar as maneiras como o sentido serve" a um jogo de poder que se explica como processo de "ocultamento e mascaramento".

$\mathrm{E}$, pelo fato de as ações ideológicas necessitarem da linguagem, o discurso assume também, no confronto ideológico, contornos peculiares de instrumento de (dis)simulação, precisamente pelos recursos que disponibiliza, entre os quais podem ser considerados não só a mistificação de que fala Mészáros, mas também a argumentação, a sedução, a persuasão, a generalização falsa, a impessoalização, a mitificação, a desfocalização, etc., o que, sem dúvida, representa um poderoso arsenal e instrumento de intervenção no conflito, especialmente se o grupo domina os meios de comunicação social.

A mediação: a língua como reflexo e o discurso como refração

A continuidade (ou a sobrevivência) do gênero humano depende, fundamentalmente, de dois processos: o da reprodução não só biológica, mas também daquilo que o homem produziu e a superação (ou a transformação) que toma como ponto de partida exatamente o que foi reproduzido, ou seja, o homem, para atuar diante das necessidades que o contínuo modificar-se da realidade social constrói, toma como referência o que historicamente resultou da atividade da humanidade.

E para que esses dois processos vitais ao gênero humano possam se realizar, os homens elaboraram um instrumento-meio de grande eficácia: a linguagem. Ela pode ser explicada

como complexo dentro da complexidade [social]: o ser social tem [...] primeiro, um caráter universal que se expreessa de tal modo que ela [a linguagem] precisa se constituir, para cada contexto, para cada complexo do ser social, como órgão e como mediação da continuidade do desenvolvimento, da preservação e da superação (LUCÁKS, 1986, v. II, p. 181). 
Isto é: o discurso, apoiado na materialidade lingüística, assume a função de, como "máquina" produtora de sentidos, garantir, através da generalização, a reprodução e, com a atividade dos indivíduos com e sobre os sentidos genéricos, a transformação. $O$ discurso constitui-se, nesta ótica, em mediação do desenvolvimento do gênero humano.

Pode-se dizer, por isso - por ser mediação de acontecimentos -, que o discurso é mediação-acontecimento que, como produtosíntese da relação do indivíduo com a língua e a objetividade social, preenche uma necessidade dos homens, quer seja em relação a sua atividade diante da natureza, quer seja frente às questões que dizem das relações entre si. E, por isso, o discurso precisa ser explicitado sempre tendo em vista que ele preenche funções que extrapolam uma imediaticidade da comunicação tomada como um fim em si.

Em outras palavras, numa função, o discurso é mediação do processo de transferência de conhecimentos e, noutra, ele se oferece para mediar tanto a produção e a avaliação de metas e objetivos, como a administração da diversidade e complexidade das relações sociais.

Não há, portanto, quando se fala em determinações sociais do discurso, como esquecer que elas se constroem e transformam permanentemente, num contraditório processo que, conforme Lukács (1986, v. II), "não se refere à simples conservação do que foi conquistado, mas também, sem deixar de fixar a conquista, a uma ininterrupta superação, onde cada etapa dessa dialética de superação [entre a conservação e a superação] efetiva a unidade contraditória da conservação e da transformação." (p. 176)

O uso da língua não deixa de orientar-se, enfim, por determinações que se referem ao desenvolvimento histórico do gênero humano, em que a uma "simples conservação" se sucede, contraditoriamente, "uma ininterrupta superação" do que deveria ser conservado.

Entendo, pois, que o redimensionamento do discurso como mediação do processo social ganha importância na concepção de que são a continuidade e a sobrevivência do grupo que dependem do processo de comunicação. A linguagem, pois, ao preencher a função comunicativa, socializa o produto do trabalho individual e possibilita, a partir dessa etapa, a fixação de objetivos e o (re)direcionamento de atividades para o grupo desenvolver-se. 
A produção de enunciados, enfim, deve ser entendida como demarcada por limites sociais e históricos em razão de dois motivos fundamentais: 1) o mesmo homem que produziu um determinado instituído social, só o fez tendo se apropriado do que já havia sido produzido, o que quer dizer que nenhum ato humano pode se eximir de uma reprodução e, por isso, o discurso só pode preencher a função de mediação do desenvolvimento do gênero humano se os sentidos estiverem historicamente "atualizados". Em outras palavras, a apropriação da generidade humana é uma condição de produção (também do discurso) historicamente determinada e, por isso, essa concepção explica a importância dos elementos extra-lingüísticos e sugere que um texto, por mais bem elaborado que seja do ponto de vista lingǘstico e estrutural, tendo perdido as cores do contexto histórico em que foi produzido e foi mediação, oferecerá enormes dificuldades para que um receptor, numa nova situação histórica, infira determinados sentidos mediadores.

A questão que se arma, porém, é de compreender as condições materiais específicas que possibilitam a mediação, ou seja, "[...] aquilo que nos interessa liga-se à questão de saber como a realidade determina o signo, como o signo reflete e refrata a realidade em transformação" (BAKHTIN, 1986, p. 41).

E se "o signo se torna a arena onde se desenvolve a luta de classes" (p.46) e se "a palavra é capaz de registrar as fases transitórias mais íntimas, mais efêmeras das mudanças sociais" (p.41), é preciso retornar à reflexão sobre a língua, com o propósito de explicitar como se dá a relação dela com o discurso, obviamente não negando-lhe a função comunicativa, mas focando-a nessa relação com a discursividade que orienta seu uso.

O que tentei, pois, problematizar, no início do texto, são os efeitos da concepção de o uso da língua se prestar apenas à comunicação e à possibilidade de interação numa dada situação, função que poderia ser interpretada não só como uma concepção reducionista, mas também, e por isso mesmo, como um apagamento de comprometimentos culturais e históricos, especialmente na dimensão do mediato que se refere à generidade humana. Isto é: o apagamento poderia estar escondendo uma luta de interesses, já que à visão redutora do discurso corresponderá uma concepção deformada do ser social do homem, pois se a linguagem serve apenas e 
inocentemente à comunicação, por que falar de valorizações, poder, conflito, ideologia ou de generidade humana?

E quando reafirmo que a função do discurso deve ser entendida como uma mediação que é imprescindível ao gênero humano no que possibilita, contraditoriamente, em termos de reprodução e de transformação, estou igualmente aceitando a concepção de língua que afirma que "A contradição [da reprodução e da transformação] nas duas direções nasce do ser social do homem. E o movimento, nessa contradição, será, por isso, o mais importante da característica da inesgotabilidade produtiva da língua" (LUKÁCS, 1986, v. II, p. 175).

Ora, a questão é saber de que modo ou qual a característica do discurso que poderá preencher essa dupla e contraditória função de mediar a preservação e a transformação.

Considero que a resposta pode estar no que Frege (1978) afirma sobre a diferença entre sentido e representação, porque permite propor, mantendo os conceitos, que o sentido corresponde a uma generalização, cuja carga informativa se refere aos traços genéricos do produto do trabalho dos homens e a representação se constitui com o acréscimo de traços singulares da coisa nomeada, o que pode ser o início de uma transformação do que o sentido reproduziu.

Isto é: "Não se pode esquecer que cada palavra, desde a mais simples do cotidiano, sempre expressa a generalidade da realidade, o gênero, [...] e não o objeto singular, [sendo] impossível encontrar, para a singularidade de qualquer realidade, uma palavra nitidamente definidora" (LUCÁKS, 1986, Vol.II, p. 170). O fato de a palavra abranger, pois, uma totalidade de indivíduos que nomeará conduz a que, através de um processo de abstração, sejam, obrigatoriamente, eliminados os traços singulares, mantendo-se apenas aqueles que são comuns a todos. Isso significa que o sentido é, em parte, genérico e, por isso, garante a comunicação entre os homens, o que, por sua vez, viabiliza o processo de manutenção de um instituído e sua superação possível.

Em resumo, o discurso, para preencher a sua dupla função, apóia-se na língua, ou seja, num conjunto de sentidos genéricos que são fruto de abstrações que realizam os indivíduos, e que sustentam as interações sociais em que atos, mesmo submetendo-se a regras, ora mais ora menos rígidas - quer lingüísticas, quer sociais - podem 
concretizar a superação necessária e salutar do que foi produzido historicamente pela coletividade.

Em outros termos:

1. A socialização do produto da atividade humana - e do discurso - está para a generalização, assim como a generalização está para condições de comunicação.

2. A generalização de que dependem as relações sociais implicam em reprodução do produto do trabalho humano.

3. A falta do traço singular na mediação discursiva convoca os indivíduos à atividade interativa que só é possível porque os sentidos genéricos fazem a mediação da superação das dificuldades que geram as múltiplas singularizações.

Fica claro, pois, que se o discurso tem um poder que é motivo de disputas, muitas vezes, ferozes e radicais, é porque, como mediação, possibilita direcionar e configurar a realidade social em termos do que se elegerá como conveniente manter e do que deverá ser modificado, o que, sem a materialidade lingüística, seria impossível.

A língua, portanto, como realidade que tem uma lógica própria de funcionamento - e que difere da do discurso - não pode ser desconsiderada quando do estudo das condições de produção ou discursividade do enunciado.

Em outros termos, a língua, como produto histórico dos homens, presta-se a ser, por seu caráter generalizante, o elo homogeneizante da heterogeneidade: o sentido genérico constitui-se como a ponte sobre a qual, apesar da fragilidade, da imprecisão e da vaguidade dos sentidos, transitam as singularidades humanas.

As atividades particulares dos indivíduos - que poderiam, devido à singularização, colocar em risco a continuidade do gênero humano -, por sua vez, pelo fato de dependerem da generalização da língua, tanto reproduzem como transformam.

Por isso, as palavras de Bakhtin (1986) e Lucáks (1986) são importantes orientações quando afirmam que a língua, enquanto conjunto estruturado de elementos dos quais o enunciante se apropria para enunciar, é reflexo da realidade social construída pelos homens. E é refração quando acionada na interação social, completando, assim, 
esse movimento paradoxal e contraditório que se instala com a produção do discurso.

Assim, considero como reflexo da realidade social o que se observa na língua:

1. Um conjunto lexical depende fundamentalmente do que os indivíduos de determinado grupo social ou comunidade fazem e produzem: o léxico de uma comunidade de pescadores, por exemplo, difere certamente do de criadores de gado.

2. Os elementos gramaticais também podem revelar costumes sociais tais como sistemas de parentesco, regras de etiqueta social, etc. Por exemplo, há línguas indígenas em que os afixos indicam os graus de parentesco.

3. Às diferenças de disposição dos lugares na hierarquização social correspondem variações da língua e que têm, por isso, mais ou menos prestígio e poder: a variedade lingüística considerada padrão ou culta vale mais do que as outras.

4. Os conflitos sociais que envolvem disputas de poderes introduzem dicotomias lexicais na língua. Exemplo: invasão $\mathrm{x}$ ocupação, marginal x marginalizado são oposições lingüísticas que refletem a heterogeneidade referencial e ideológica.

5. Os interesses que movem o(s) indivíduo(s) ao enunciar(em) levam-no(s) a um esforço específico para conseguir a adesão do(s) outro(s), o que se reflete, na língua, como escalaridade dos itens lexicais que se organiza a partir da força de impacto e de convencimento. Por exemplo, a escalaridade de delinqüente, bandido, facínora, monstro, marginal, etc., pelo efeito que pode produzir cada escolha, é pista da necessidade que o complexo social instaura: a de o indivíduo ter que convencer e buscar a adesão do outro a um sistema de referências. Do mesmo modo, são reflexo dessa necessidade, os modalizadores e os operadores argumentativos.

6. A polissemia do signo lingüístico reflete a heterogeneidade social porque a diversidade cultural e referencial leva a que as palavras tenham sentidos singulares e, até, algumas vezes, genéricos diferentes, dependendo do grupo em que circulam. 
7. O sentido genérico da palavra é resultado da atividade dos indivíduos que precisam, diante da singularidade das coisas, realizar abstrações para poderem se comunicar.

8. Os recursos expressivos da língua refletem a atividade interativa individuante dos interlocutores. Os pronomes pessoais eu e $t u$, por exemplo, indicam as alternâncias de papéis na interação. Do mesmo modo, os sentidos dos dêiticos - como aqui, ali, este, aquele, etc. dependem de quem toma ou recebe a palavra na interação. Benveniste (1976) desenvolveu, observando esse tipo de elemento lingüístico, a idéia de que a língua apresenta marcas da individuação do enunciante, ou seja, de sua subjetividade.

Os exemplos alistados representam, pois, a pressão da generidade humana sobre a língua. $\mathrm{O}$ uso, contudo, da língua, significa uma refração, processo que abre a possibilidade para inúmeros jogos e arranjos, precisamente, porque o reflexo é produto de "jogos" e "arranjos" sociais. Isto é: o que é reflexo da processualidade do gênero humano, torna-se, num movimento de retorno, um conjunto de recursos expressivos dos quais, pode-se valer, por exemplo, a ação ideológica.

Alisto, pois, alguns, exemplos de refração:

1. Os elementos da língua prestam-se à organização de estratégias discursivas que podem representar um recurso valioso no jogo de poder, como são os casos, por exemplo, da sedução, da mentira, da disposição estudada do arranjo, etc. Assim, em 'Ele está livre' há um pressuposto de que 'Ele outrora não estava livre', enquanto que em 'Ele é livre' esse pressuposto não existe. Já em 'Ele é livre agora' há novamente um pressuposto contido. Outro exemplo interessante é o caso da ironia em que o enunciante acusa, mas não se expõe à crítica: dizer, por exemplo, 'Como você foi inteligente' para alguém que acaba de fazer uma bobagem, se refere à implicitação de uma acusação da qual o enunciante não pode ser responsabilizado diretamente.

2. Os elementos da língua, por permitirem diferentes modos de dizer uma mesma coisa, podem ser usados para produzir efeitos favoráveis ou o contrário. Por exemplo, numa competição entre dois indivíduos, o melhor colocado pode ser 
nomeado como primeiro ou penúltimo, e o outro como segundo ou último. Do mesmo modo, o uso de adjetivos como bom e mau, honesto e desonesto, justo e injusto, etc. requer a marcação de uma referência externa à língua e que o enunciante pode escolher estrategicamente para beneficiar interesses seus e de seu grupo.

3. A utilização de determinados itens lexicais que são resultado do embate ideológico permite, por exemplo, classificar as ações do MST ou como invasão ou como ocupação. Da mesma forma, alguém pode classificar um indivíduo como marginal ou marginalizado, determinando um ou outro tipo de hierarquização de valorações.

4. A impessoalização é uma estratégia ideológica que, valendose da generalização, visa a retirar ou o peso da responsabilidade do enunciante, como em 'A sociedade está a exigir um governo forte (ditadura)', ou a força representativa de indivíduos e grupos através do uso de pronomes "genéricos" que implicitam uma exclusāo como, por exemplo, eles, ou, ainda essa (gente) - expressões que podem representar uma dimensão pejorativa de um lugar na hierarquização social.

5. A utilização do caráter polissêmico e ambíguo das palavras, como, por exemplo,um candidato negro, usar, como slogan eleitoral contra um adversário branco 'Não vote em branco, vote no escurinho'. No enunciado pode-se ler um duplo preconceito racial

6. O emprego de expressões vagas e que admitem uma certa liberdade de jogo significativo que, bem utilizada, pode produzir fortes efeitos de sentido, tais como, por exemplo, nos casos de 'A terra deve ter uma função social' ou 'Essa mulher não merece pensão alimentícia porque tem capacidade de trabalho'. A vaguidade possibilita, ainda, uma outra estratégia do enunciante: ele pode produzir com ela efeitos de suspeição e de desconfiança, como, por exemplo, em 'O MST recebe ajuda financeira de instituições estrangeiras'

7. A escolha - comprometida e comprometedora - de itens lexicais dentro da escalaridade lingüística, freqüente, por exemplo, nos inquéritos policiais, como no caso de infrator, 
delinqüente, bandido, facínora, monstro, etc. cuja utilização imprime maior ou menor força de acusação já antes do julgamento formal.

8. A mistificação que atua sobre dissociações semânticas do tipo natural $x$ cultural, aparência $x$ essência, etc. para fixar o par mutável $x$ imutável e, furtando-se a uma lógica explicativa, produzir, intencionalmente, falsas generalizações e "justificativas". Por exemplo, é complicado aceitar que 'É natural que haja ricos e pobres.'

9. Um outro tipo de generalização falsa refere-se ao processo em que o enunciante faz passar por geral o que é do nível do singular e, com isso, arma um raciocínio que privilegia interesses de seu grupo. Dizer, por exemplo 'Todos os políticos são corruptos' pode não ser apenas uma denúncia, mas também uma estratégia que visa a atender os interesses de quem não quer que haja eleições.

10.A mitificação vale-se da repetição para cristalizar sentidos de expressões, como faz, por exemplo, a imprensa quando anuncia que 'Informa com imparcialidade', ou quando se diz que 'Qualquer trabalho dignifica o homem'. A cristalização impede ou dificulta a desconstrução dos sentidos mitificadores e possibilita a manutenção de uma dada hierarquização social.

11. A implicitação, entendida como um processo em que se inclui um sentido ou uma avaliação de forma sutil e que pode ridicularizar ou condenar como, por exemplo, quando se diz 'Isso é serviço de negro'. Não é difícil perceber, em enunciados como esse, um nítido propósito de hierarquizar de modo que o segmento social dos negros ocupe um espaço inferiorizado e de menor prestígio.

12.A implicação representa um processo diferente da implicitação, embora trabalhe também com o subentendido. É um processo argumentativo e arma uma lógica do tipo se...então, cujas conseqüências podem ser muito bem avaliadas em enunciados como 'Se os machos em muitas espécies de animais, uma vez excitados, usam até a força para fazer sexo, então estuprar também deve ser considerado um ato natural do homem'. 
13.A higienização deve ser entendida como uma estratégia que atua sobre a característica generalizante da linguagem para retirar a carga condenatória dos atos praticados ou pelo enunciante ou pelos membros de seu grupo. É exemplo disso um policial afirmar que teve que matar gente por 'estar cumprindo ordens'

14.A (des)focalização deve ser considerada um importante recurso discursivo nas ações ideológicas já que, valendo-se de determinados operadores argumentativos, pode colocar em destaque um ou outro sentido. O operador mas pode, por exemplo, desfocalizar a primeira parte do enunciado e destacar a segunda como em 'O MST é um movimento social, mas suas ações estão fora da lei'.

15.A citação do discurso do outro envolve inúmeras formas comprometedoras de inclusão (Bakhtin, 1986) de vozes, através dos verbos citantes como, por exemplo, quando, ao usar o enunciado 'Se a pena de morte resolver a violência e nunca atingir um inocente, então, sou a favor', alguém, com óbvios interesses, faz o recorte estratégico e escolhendo entre verbos citantes como afirmar, admitir, ponderar, negar, condicionar, sugerir, assumir, destacar, dizer, etc., produz 'Fulano disse que é a favor da pena de morte'.

16.A manipulação de dados estatísticos: Um tratamento estatístico só é possível marcando uma determinada referência em relação à qual se constrói a quantificação, o que possibilita uma estratégia para minimizar, por exemplo, um problema, cotejando estrategicamente números, com o quantificador apenas, tais como em 'É preciso considerar que $87 \%$ da população tem emprego formal, apenas 13\% não tem', etc.

17.A falsa analogia é uma estratégia que tem por objetivo confundir a avaliação do interlocutor como, por exemplo, na "justificativa" que busca amenizar um problema social em 'A prostituição é igual a qualquer outro trabalho'.

Outrossim, os exemplos de como se materializam como reflexo as determinações da generidade humana, e de como, na mediação, se concretiza o processo de refração desse reflexo, dão a exata dimensão da relação entre dois complexos distintos, mas interdependentes, como a língua e o discurso. 
Penso que os recursos lingüísticos e discursivos apresentados são comumente utilizados pelos indivíduos nas ações ideológicas e representam sempre um instrumento extremamente poderoso, precisamente, porque armam estratégias de manipulação para instalar um ideal de sociedade.

Em resumo, cabe dizer que há um reflexo social na materialidade discursiva e, ao mesmo tempo, uma refração ou um retorno no processo de mediação. $\mathrm{E}$, do mesmo modo que se entende que a língua não existe sem os atos interativos dos homens e que não há possibilidade de ato interativo sem língua, também se pode assumir que não há língua sem discurso, nem discurso sem língua e sem atividade humana.

\section{Referências}

AUSTIN, J. L. How to do things with words. N.York: Oxford Univ.Press, 1965.

BAKHTIN, M. Marxismo e filosofia da linguagem. São Paulo: Hucitec, 1986.

BAKHTIN, M. Estética da criação verbal. São Paulo: Martins Fontes. 1992.

BENVENISTE, E. Problemas de lingüística geral. São Paulo: Nacional/EDUSP, 1976.

DUCROT, O. Princípios de semântica lingüística: dizer e não dizer. São Paulo: Cultrix, 1977.

FREGE, G. Lógica e filosofia da linguagem. São Paulo: CultrixEdusp, 1978.

FREIRE, P. Educação como prática da liberdade. 20. ed. Rio de Janeiro: Paz e Terra, 1991.

GNERRE, M. Linguagem, escrita e poder. São Paulo: Martins Fontes, 1985.

GOFFMAN. E. A Representação do eu na vida cotidiana. Petrópolis: Vozes, 1985.

GOLDMANN, L. Dialética e cultura moderna. Rio de Janeiro: Paz e Terra, 1979. 
GRICE, H.P. Logic and Conversation. In: COLE,P.\&MORGAN,J.L. (eds.). Syntax and semantics. vol.8. New York: Academic Press. 1975, p. 41-48,

HELlER, A. O Cotidiano e a história. Rio de Janeiro: Paz e Terra, 1972.

LESSA, S. Trabalho e ser social. Mimeo., s.d.

LUKÁCS, G. Zur Ontologie des gesellschaftlichen Seins. (V. I e II) Darmstad: Luchterhand. 1986.

MÉSZÁROS, I. Filosofia, Ideologia e Ciência Social. São Paulo: Ensaio, 1993.

POPHAM, W.J. \& BAKER, E.L. Como planejar a seqüência do ensino. Porto Alegre: Globo, 1976.

SEARLE, J. Speech Acts. Cambridge: Cambridge Univ.Press, 1969. THOMPSON, J.B. Ideologia e cultura moderna. Petrópolis: Vozes, 1995.

WARAT, L.A. A ciência jurídica e seus dois maridos. Santa Cruz do Sul: Fisc, 1985 